\title{
Start-up in Microgravity and Local Thermodynamic States of a Hybrid Loop Thermosyphon/Pulsating Heat Pipe
}

\author{
Mauro Mameli ${ }^{1 *}$, Andrea Catarsi ${ }^{1}$, Daniele Mangini ${ }^{2}$, Luca Pietrasanta $^{3}$, Nicholas Michè ${ }^{3}$, Marco Marengo ${ }^{3}$, \\ Paolo Di Marco ${ }^{1}$, Sauro Filippeschi ${ }^{1}$ \\ ${ }^{1}$ University of Pisa, LargoLucio Lazzarino 2, 56122 Pisa, Italy. \\ ${ }^{2} \mathrm{HE}$ Space Operations BV for ESA, NL-2200AG Noordwijk, The Netherlands. \\ ${ }^{3}$ School of Computing, Engineering and Mathematics, University of Brighton, Lewes Rd, Brighton BN2 4AT, UK. \\ *correspondingauthor: mauro.mameli@unipi.it
}

\begin{abstract}
A wickless passive two phase closed loop heat transfer device especially designed for a future implementation on the heat transfer host module of the International Space Station is tested in relevant environment on board a parabolic flight. The tube internal diameter $(3 \mathrm{~mm})$ is larger than the static capillary threshold evaluated in normal gravity for this working fluid (FC-72), leading the device to work as a loop thermosyphon on ground and in hypergravity conditions, and as a Pulsating Heat Pipe when micro-gravity occurs. Novel start up tests, where the heat load has been provided after the occurrence of microgravity, show that the 20s microgravity period is enough for the device activation and, most important, that the device activation is purely thermally induced and not affected by the previous acceleration field. Two miniaturized pressure transducers and direct fluid temperature measurement via two micro-thermocouples, allow to provide a detailed insight on the fluid local thermodynamics states both in the evaporator and in the condenser zone during microgravity. It is shown that the two-phase fluid close to the evaporator and the condenser is subjected to several degrees (up to $5 \mathrm{~K}$ ) of superheating or subcooling. The level of subcooling seems to increase with the heat input level both in terms of temperature difference and in terms of percentage time with respect to the whole microgravity period.
\end{abstract}

Keywords: Pulsating Heat Pipe; Start-up; Thermodynamic States; Microgravity; Intemational Space Station.

\section{INTRODUCTION}

Spacecrafts and satellites thermal management is a challenging issue, not only for the conditions of the open space (microgravity, vacuum, low temperatures), but also for the complex requirement in terms of compactness, weight, durability and heat transfer capability [1]. Various heat pipes (Grooved Heat Pipes, Sintered Heat Pipes, Loop Heat Pipes, Capillary Pumped Loops) have already been qualified as "flight proven” through successful operations in Space missions [2]. In the last two decades, wickless two-phase passive devices, known as Pulsating Heat Pipes (PHP) or Oscillating Heat Pipes, have been intensively investigated in several fields of application, due to their potential advantages in terms of flexibility, surface adaptability and low cost [3]. The thermal response in microgravity environment is particularly interesting because it allows to eliminate the effect of gravity on the device thermal behaviour and understand that, for a capillary planar PHP there is practically no difference from the thermal response obtained during microgravity and the vertical to horizontal tilting manoeuvre on ground[4]. Several investigations on capillary PHPs has been performed in the last years both on parabolic flights by Gu et al. [5][6], by Ayel et al. [7] by Taft et al. [8], sounding rocket campaigns by De Paiva et al. [9][10] and even on orbit [11] [12] by the group of Prof. Daimaru. This last experiment is very important because it provides long term experiments in relevant environment bringing the PHP to a higher technological readiness level for space (TRL= 7).

Gu et al. [5][6] were the first to speculate on the possibility to increase the PHP internal diameter above to increase the heat transfer capability. Indeed, in microgravity conditions, the ratio between buoyancy forces and 
surface tension forces decrease, allowing to exploit larger diameter tubes with respect to the capillary limit on ground derived by the balance of forces in the Bond number. A concept of hybrid Loop Thermosyphon/Pulsating Heat Pipe (LT/PHP) for space applications was tested aboard of parabolic flights by Mangini et al. [13][14] in a tubular configuration filled with FC-72, by Ayel et al. [15] in the form of a copper flat LT/PHP again filled with FC-72, by Cecere et al. [16] with the same device filled with self-rewetting fluids, and on a tubular hybrid device mounted on a sounding rocket by Mameli et al. filled with perfluorohexane (pure FC-72) [17]. In allthe experimentaltests the device, which was already operating as a Loop Thermosyphon before the zerogravity period, responds to the occurrence of microgravity with a flow pattern transition from a stratified to a slug-plug regime, and that the flow pressure signal exhibits an oscillating trend throughout the entire 0 -g period. On the other hand, due to the experimental conditions, and due to the thermal inertia, it has not been possible to reach a steady state condition, i.e. the averaged value of the temperature and pressure is still varying within the time lag of the microgravity period. Therefore, a long-term microgravity environment (i.e. suborbital flights, satellites, space stations) is necessary to evaluate the actual performance of this kind of LT/PHP at a pseudo-steady state (i.e. Pseudo-steady state is reached when all temperature signals show an average value constant in time). This paper presents the concept of a LT/PHP especially designed for a future implementation on the heat transferhost module (HTH) of the International Space Station (ISS) [18] in 2021, and its thermal characterization in a variable gravity field, obtained during the $67^{\text {th }}$ ESA parabolic flight campaign, combining both technological and basic research targets. From the technological point of view, despite the microgravity period is here once again limited, the present experiment allowed to put light on one of the most important technical issues that was still unsolved: the LT/PHP start-up during the zero-gravity period. From the basic research point of view, micro-thermocouples and miniaturized, flush mounted, pressure transducers, were used to measure the localthermodynamic state of the fluid (simultaneous pressure and temperature) close to the evaporator and the condenser section. The continuous existence of local thermodynamic non-equilibrium states in the two-phase fluidic system is the very basis of the LT/PHP working principle. It is indeed necessary to have a finite temperature difference along the device, obtaining a purely thermally induced flow motion [19]. Even though this is one of the most crucial aspects for the PHP understanding and modeling, the proper consideration of non-equilibrium thermodynamic states of the liquid/vapor system in an actual multi-turn PHP is still incomplete and may create misleading evaluations. For instance, Bruce et al. [20] first assume that a single fluid pressure measurement is representative of the whole PHP and corresponds to the saturation pressure, then they compute the relative saturation temperature and compare such value with the external tube temperature of the PHP in the evaporator and in the condenser. In real systems, the local fluid thermodynamic state is far from equilibrium conditions and the local assumption of superheated vapor and saturated vapor are mutually exclusive [21]. Experimental evidence of themodynamic non-equilibrium can be found in the literature regarding a confined liquid-vapor state inside a capillary channel [22][25], showing that the vapor within a bubble can be superheated. To the best authors' knowledge, the detection of superheated and subcooled levels in an actualPHP hasbeen only reported very recently by Jun et al. [26], for a Micro Pulsating Heat Pipe (MPHP) in the form of a flat plate. The work shows several degrees of superheating for the vapor phase but few data on the fluid subcooling level. The present work aims at filling this gap showing the temporal trends both for the superheated and subcooled thermodynamic states.

The research objectives of the present paperare:

- Prove that the device operation during microgravity is purely thermally induced and it is not dominated by the flow inertial effect that may be already present before the micro-gravity period.

- Characterize the fluid local thermodynamic states close to the evaporator and the condenser zone, by developing a method to measure the temperature difference between the actual fluid temperature and the saturated condition (subcooling and superheating levels) during the micro-gravity period.

The outcomes related to the above points are thoroughly described in the following sections, unveiling new insights on the LT/PHP working principles, and providing data for the validation of actual numerical models. 
Table 1: main details and outcomes of the previous studies in the literature.

\begin{tabular}{|c|c|c|c|c|c|c|c|c|}
\hline Author, (year) & $\begin{array}{l}\text { Exp. platform } \\
\text { (agency), 0-g } \\
\text { period } \\
\end{array}$ & Type & $\begin{array}{c}\text { Mate rial, layout, } \\
\text { enve lope, } N^{\circ} \text { of } \\
\text { chan./heated zones }\end{array}$ & $\begin{array}{l}\text { Chan. cross } \\
\text { sec., diam. } \\
\text { [mm] }\end{array}$ & $\begin{array}{l}\text { Working } \\
\text { fluid }\end{array}$ & $\begin{array}{l}\text { Vol. } \\
\text { Filling } \\
\text { Ratio }\end{array}$ & $\begin{array}{l}\text { Heat } \\
\text { Input } \\
{[\mathrm{W}]}\end{array}$ & Main outcomes \\
\hline Mameli et al. (2014) [4] & $\begin{array}{l}\text { Parabolic flight } \\
\text { (ESA), } 22 \mathrm{~s}\end{array}$ & Capillary PHP & $\begin{array}{c}\text { Copper, planar, tube, } \\
32 / 16\end{array}$ & Circular, 1.1 & FC-72 & 0.5 & $10-100$ & $\begin{array}{l}\text { For a capillary planar PHP there ispractically no difference from the } \\
\text { thermal response obtained during microgravity and the vertical to } \\
\text { horizontal tilting manoeuvre on ground. The devicetested in } \\
\text { horizontal is not influenced by variation of gravity level }\end{array}$ \\
\hline Gu et al. (2004) [5][6] & $\begin{array}{l}\text { Parabolic flight } \\
\text { (JAXA) }\end{array}$ & Capillary PHP & Copper, flat plate & $\begin{array}{l}\text { Rectangular } \\
1 \times 1\end{array}$ & R114 & $0.5-0.7$ & $1.4-5.9$ & $\begin{array}{l}\text { under reduced gravity, theheat pipes showed better operating and } \\
\text { heat transport performances than under normal and hyper-gravity }(*) \text {. }\end{array}$ \\
\hline Ayel et al. (2015) [7] & $\begin{array}{l}\text { Parabolic flight } \\
\text { (ESA), 22 s }\end{array}$ & Capillary PHP & $\begin{array}{l}\text { Planar, copper, flat } \\
\text { plate, } 24 / 12\end{array}$ & $\begin{array}{r}\text { Rectangular } \\
1.6 \times 1.7\end{array}$ & FC-72 & 0.5 & $30-180$ & $\begin{array}{l}\text { Compared to [4] the device showed a similar thermal-hydraulic } \\
\text { behavior but a quicker response to gravity variations with a steady- } \\
\text { stateregimereached in only } 22 \text { s of microgravity, at least from a } \\
\text { hydraulic point of view. }\end{array}$ \\
\hline Taft et al. (2015) [8] & $\begin{array}{l}\text { Parabolic flight } \\
\text { (NASA), 25s }\end{array}$ & Capillary PHP & $\begin{array}{l}\text { Planar, aluminum, } \\
\text { flat plate, } 40 / 20\end{array}$ & $\begin{array}{r}\text { Rectangular } \\
1.3 \times 1.3\end{array}$ & Acetone & 0.8 & $\begin{array}{l}200,300 \\
450\end{array}$ & $\begin{array}{l}\text { If the PHP is terrestrially orientation independent, it is also likely to } \\
\text { be gravity-independent. If the PHP is not terrestrially independent, it } \\
\text { is likely to perform better in a microgravity environment }(*) \text {. }\end{array}$ \\
\hline De Paiva et al. (2010) [9] [10] & $\begin{array}{c}\text { Sounding Rocket } \\
\text { (Brazil), 400s }\end{array}$ & Capillary PHP & $\begin{array}{c}\text { Copper, planar, tube, } \\
32 / 16\end{array}$ & $\begin{array}{l}\text { Circular, } \\
1.27\end{array}$ & Acetone & (n.d.) & 20 & $\begin{array}{l}\text { The device exhibits a constant wall temperat ure fluct uation during } \\
\text { the whole microgravity period without any stopover but isnot able to } \\
\text { reach a pseudo steady state. More tests must be conducted to qualify } \\
\text { PHP technology for space application. }\end{array}$ \\
\hline Daimaru et al. (2017) [11][12 & $\begin{array}{c}\text { Satellite (JAXA), } \\
\sim 4 \text { years }\end{array}$ & $\begin{array}{l}\text { Capillary PHP with } \\
\text { check valves }\end{array}$ & $\begin{array}{l}\text { Stainless steel, 3D, } \\
\text { tube, } 10 / 5\end{array}$ & Circular, 0.8 & R134a & 0.45 & $2.6-13.7$ & $\begin{array}{l}\text { First long-term characterization of a capillary PHP in space } \\
\text { conditions. Performances match that on ground. } \\
\text { Start-up difficulties due to the initial phase distribution. }\end{array}$ \\
\hline Mangini et al. (2015) [13] [14] & $\begin{array}{l}\text { Parabolic flight } \\
\text { (ESA), 22s }\end{array}$ & Hybrid LT/PHP & $\begin{array}{l}\text { Aluminum, planar } \\
\text { tube, } 10 / 5\end{array}$ & Circular, 3 & FC-72 & 0.5 & $10-160$ & $\begin{array}{l}\text { In normal gravity the device works as a Loop Thermosyphon, while } \\
\text { during microgravity it works in the typical PHP mode, with } \\
\text { oscillating slug/plug flow; } \\
\text { A non-symmetrical heating promotes a circulation in a preferential } \\
\text { direction, while the symmetrical heating causes an intermittent } \\
\text { working mode when the device is not gravity assisted. }\end{array}$ \\
\hline Ayel et al. (2019) [15] & $\begin{array}{l}\text { Parabolic flight } \\
\text { (ESA) } \sim 22 \mathrm{~s}\end{array}$ & Hybrid LT/PHP & $\begin{array}{c}\text { Copper, planar, flat } \\
\text { plate, } 22 / 11\end{array}$ & $\begin{array}{r}\text { Rectangular } \\
2.5 \times 2.5 \\
\end{array}$ & FC-72 & 0.5 & $20-150$ & $\begin{array}{l}\text { Visualization allows to assess that for the hybrid LT/PHP high } \\
\text { velocity oscillationsare more probable with the consequent break-up } \\
\text { of the liquid menisci and a lower heat power limit for dry-out. }\end{array}$ \\
\hline Cecere et al. (2018) [16] & $\begin{array}{l}\text { Parabolic flight } \\
\text { (ESA), 22s }\end{array}$ & Capillary PHP & $\begin{array}{l}\text { Copper, planar, flat } \\
\text { plate 24/12 }\end{array}$ & $\begin{array}{l}\text { Rectangular } \\
\quad 3 \times 3\end{array}$ & $\begin{array}{l}\text { Self- } \\
\text { Rewetting } \\
\text { Fluids }\end{array}$ & 0.5 & $0-200$ & $\begin{array}{l}\text { For low power input, the PHP filled with pure water is not able to } \\
\text { work under low-g conditions, because the evaporator immediately } \\
\text { exhibits dry-out conditions, while the PHP filled with the self- } \\
\text { rewett ing fluid still operates during themicrogravity phase. }\end{array}$ \\
\hline Mameli et al. (2019) [17] & $\begin{array}{c}\text { Sounding Rocket } \\
\text { (ESA), } \sim 120 \mathrm{~s}\end{array}$ & Hybrid LT/PHP & $\begin{array}{l}\text { Aluminum, 3D } \\
\text { staggered, tube, } \\
28 / 14 \\
\end{array}$ & Circular, 3 & Perflorhexane & 0.5 & 200 & $\begin{array}{l}\text { The device exhibits a constant fluid pressure and wall temperat ure } \\
\text { fluct uation during the whole microgravity period without any } \\
\text { stopover but is not able to reach a pseudo steady st ate. More tests } \\
\text { must be conducted to qualify PHP technology for space application. }\end{array}$ \\
\hline
\end{tabular}

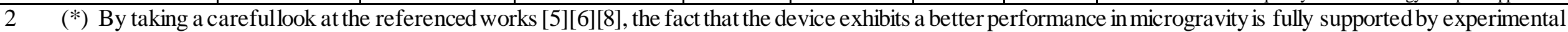

3 evidence only when compared to the top-heated mode (anti-gravity) performance on ground. 


\section{EXPERIMENTS}

\subsection{Test cell}

The device is made of an annealed aluminum (6060 alloy) tube with an inner and outer diameter of 3 and $5 \mathrm{~mm}$, respectively. The closed loop is folded in a staggered 3D configuration with 14 turns (8mm bending radius) in the evaporator zone, as shown in Figure1a. The geometry (overall size of the PHP: 220x80x25 mm) was selected to fit this device in the Heat Transfer Host preliminarily designed for the experiment on the International Space Station.

An aluminum T-junction on the top hosts one miniature pressure transducer(Keller ${ }^{\circledR}$ PAA-M5-HB, 1 bar abs, $0,2 \%$ FSO accuracy) as well as the vacuum and filling micro-metering valve (IDEX ${ }^{\circledR}$ Upchurch Sc. P-447). Two brass connections allow to connect a transparent sapphire tube (Precision Sapphire Technologies ${ }^{\circledR}$, length $140 \mathrm{~mm}$, same OD/ID of the aluminum tube) with the aluminum tube, and to host two K-type micro-themocouples (Omega ${ }^{\circledR}$ KMTSS-IM025E-150, bead diameter $0.25 \mathrm{~mm}$, response time $0.1 \mathrm{~s}$ with $95 \%$ confidence) for the fluid temperature measurement (red and blue " $\mathrm{F}$ " bullet in Figure1b), as well as another miniature pressure transducer close to the evaporator section (green "P" bullet in Figure1b). The transparent tube allows to visualize the flow motion and to perform direct infrared temperature measurements of the fluid as already shown from the same authors [27][28]. Two aluminum heat spreaders $(100 \times 12 \times 10 \mathrm{~mm})$ are brazed on the tube in the evaporator zone (Figure 1), holding two ceramic Ohmic heaters (Innovacera ${ }^{\circledR}$, electrical resistance $18 \Omega \pm 10 \%$ ). The wall-to-fluid heated area $\left(15.83 \mathrm{~cm}^{2}\right)$ is evaluated asfollows

$$
A_{w f}=N L_{e} \pi D
$$

Where $N$ is the number of heated sections (14 in the present case), $L_{e}$ is the length of the evaporator section (12 $\mathrm{mm}$ ) and $D$ is the internal tube diameter. The heating power is provided by a programmable power supply (GWInstek $^{\circledR}$, PSH-6006A) from a minimum of $18 \mathrm{~W}$ to a maximum of $182 \mathrm{~W}$, corresponding to an average wall-tofluid heat flux from 1.10 to $11.43 \mathrm{~W} / \mathrm{cm}^{2}$.

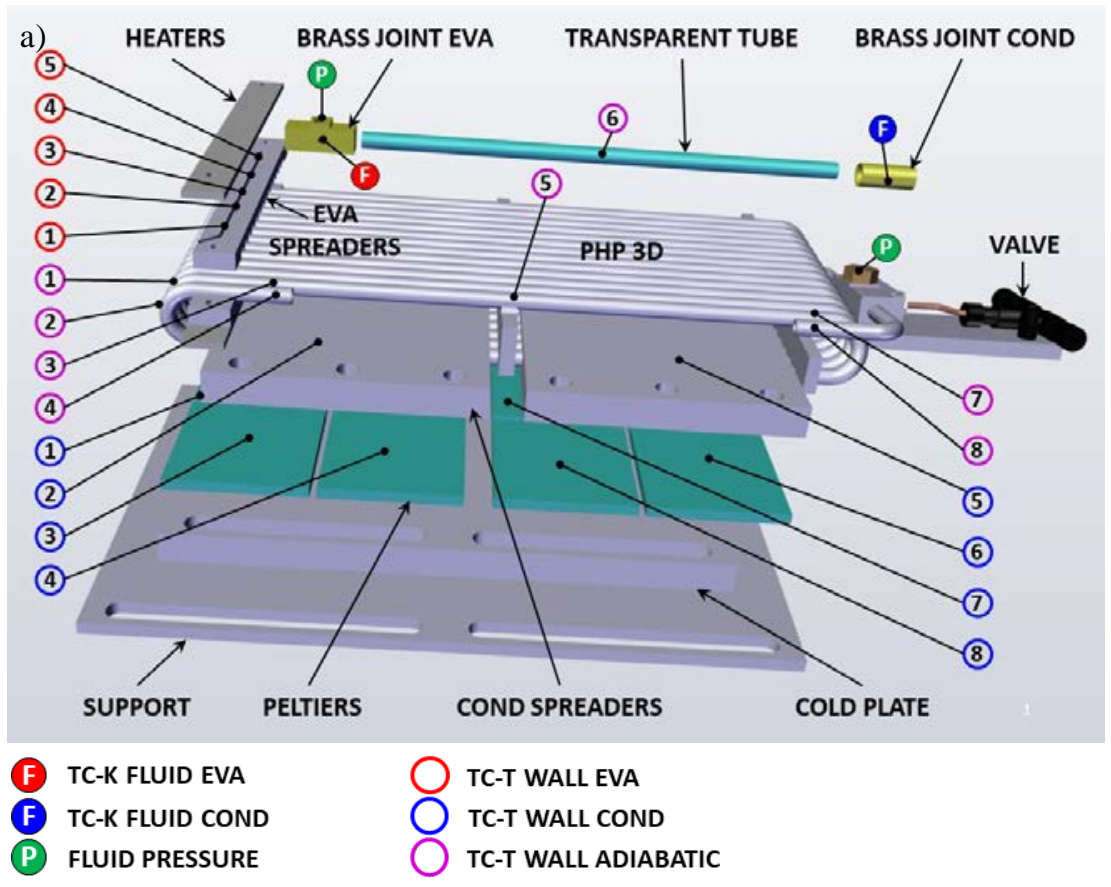

b)

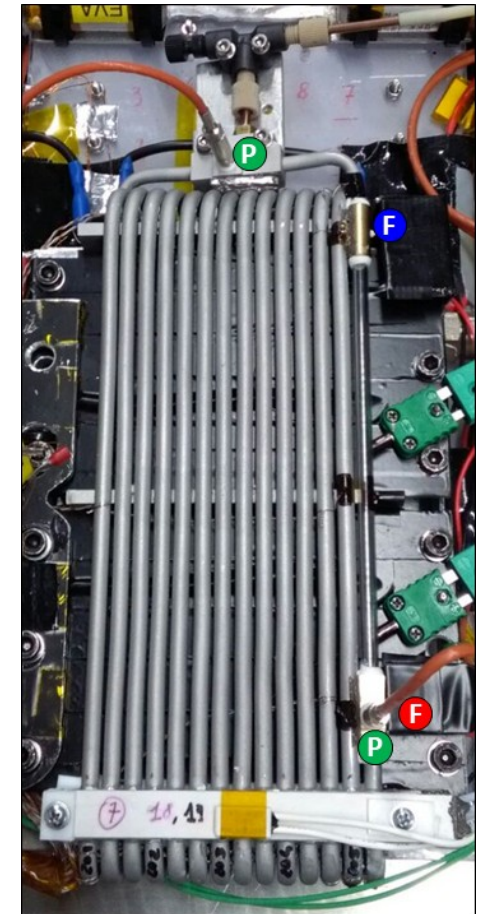

Figure 1: Test cell with thermocouples and pressure transducers location, a) 3D CAD exploded view, b) actual front view. 
means of an array of 8 Peltier cells, 40 x $40 \mathrm{~mm}$ each with a maximum cooling power per element of $82.2 \mathrm{~W}$ (at $\Delta \mathrm{T}=0$ and $\operatorname{Imax}=8.4 \mathrm{~A}$, Adaptive Thermal Management $\left.{ }^{\circledR}, \mathrm{ETH}-127-14-11-\mathrm{S}\right)$. The array is divided in two branches powered by the two channels available on the PID control system (Meertstetter Engineering ${ }^{\circledR}$, TEC 1123). A single-phase auxiliary cooling loop has beenused to dissipate the waste heat of the Peltier cells, coupling the hot side of eachelement with a high-performance cold plate (Aavid Thermalloy ${ }^{\circledR}$ ). Five T-type thermocouples are located between the evaporator spreader and the heater (see the groove in Figure 1a); six are located between the Peltier cold side and the condenser aluminium heat spreader (Figure 1a); two on the condenser heat spreader just behind the sapphire tube; seven are located on the tube extemal wall (purple pointsin Figure 1a).

FC-72 is a clear, colorless, fluorinhert liquid. It is thermally and chemically stable, compatible with most of the materials, non-flammable and non-toxic. For the low risk connected to the handling and heating of this fluid, the implementation of a test-cell with FC-72 onboard of a Parabolic Flight is considered safe. Regarding its thermophysical properties it shows good $\partial P \partial \Gamma$, which characterise the capacity of the fluid to induce oscillatory behaviour, which can guarantee good performance at the start-up and over the temperature range $0-70{ }^{\circ} \mathrm{C}$ [29]. The low value of latent heat of vaporization reduces the maximum heat flux applicable without occurrence of dryout compared to alcohols or ketones but ease once again the start up at low heat loads. The low surface tension allows to design a hybrid PHP with a reasonably small diameter [17].

To appreciate how the simultaneous fluid pressure and temperature measurement is achieved, an ad hoc brass T-junction has been designed with the double purpose of coupling the aluminium tube with the sapphire insert and at the same time it is housing the sensing tip of the fluid-side thermocouple and the pressure transducer head. A sketch of the brass T-junction, which is located at the exit of the evaporator zone, is shown in figure 2.
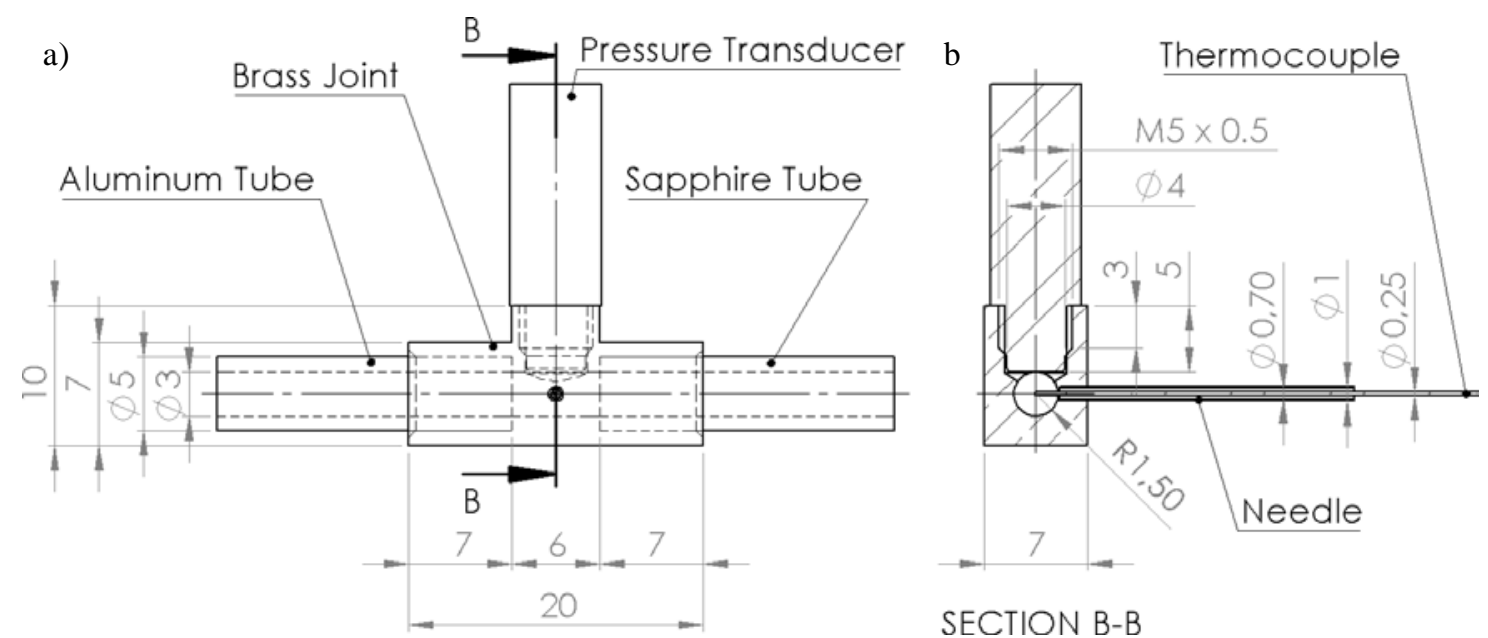

Figure 2: Mechanical drawings of the brass T-junction at the evaporator: a) local side view; b) channel cross section (all dimensions in $\mathrm{mm})$.

The brass joint ends are milled $(7 \mathrm{~mm})$ to host the aluminum and the sapphire tubes, without introducing any discontinuity in the flow path. The same is for the pressure transducer and the thermocouple: the first is flush mounted by means of a M5 threaded hole; the second one is embedded inside a needle $(1 \mathrm{~mm} / 0.7 \mathrm{~mm}$ outer/inner diameter) which is then inserted in a lateral $1 \mathrm{~mm}$ hole in the brass joint so that the thermocouple bead resides in the channel center and faces the pressure transducer. All sealings are obtained by means of low outgassing epoxy glue (Henkel Loctite ${ }^{\circledR}$ 9492). It is also important to mention that the glue fills the thin gap between the thermocouple and the needle internal surface to insulate the thermocouple from the surroundings. After vacuuming down to $0.01 \mathrm{~Pa}$, the device is partially filled with $22 \pm 0.2 \mathrm{ml}$ of FC-72 (50 $\pm 1 \%$ vol.). A data acquisition system (National Instruments ${ }^{\circledR}$, NI-cRIO-9074, NI-9264, NI-9214, 2xNI-9205, NI-9217, NI-9472) is connected to a laptop, records the thermocouples and themistors signal at $50 \mathrm{~Hz}$, and the pressure transducers signal at $200 \mathrm{~Hz}$, via a LabView ${ }^{\circledR}$ software. The transparent section is investigated by means of a grey scale compact fast camera (Ximea ${ }^{\circledR}$, USB3 XIQ-093, resolution 1280x1024, up to $400 \mathrm{fps}$. The high-speed camera is 
synchronized via software with the pressure signals and connected to an ultra-compact PC (Intel ${ }^{\circledR}$ NUC D54250WYB) storing images up to $200 \mathrm{fps}$. Error! Reference source not found. shows the uncertainty related to all the measured parameters. All the thermocouples are calibrated via a thermal chamber (BINDER ${ }^{\circledR}$ ) and a reference four wire Pt-100 (ITS-90 standard, max. error 0.035K). The uncertainty analysis has been performed according to Moffat [30] as thoroughly described in a previous work by that performed the same measurements using the same peripheral devices (power supply and acquisition system) [31], and the results in terms of maximum errors are listed in Table 2.

Table 2: acquired parameters and uncertainties, TCrelates to thermocouples, PT refers to the pres sure transducers.

\begin{tabular}{|c|c|c|}
\hline Parameter & Specs & Max error \\
\hline Tube wall temperature & T-Type Thermocouple $(0.5 \mathrm{~mm}$ bead diameter $)$ & $\pm 0.1^{\circ} \mathrm{C}$ \\
\hline Fluid temperature & $\begin{array}{c}\text { Omega }{ }^{\circledR} \text { KMTSS-IM025E-150 K-Type thermocouple } \\
(0.25 \mathrm{~mm} \text { bead diameter })\end{array}$ & $\pm 0.2^{\circ} \mathrm{C}$ \\
\hline Fluid pressure & Keller $^{\circledR}$ PAA-M5-HB, 1 bar abs & $\pm 500 \mathrm{~Pa}$ \\
\hline Power input & $\mathrm{GW}^{\mathrm{G}}$-Instek ${ }^{\circledR}, \mathrm{PSH}-6006 \mathrm{~A}$ & $\pm 3 \mathrm{~W}$ \\
\hline
\end{tabular}

The test cell, the computers, the electrical and cooling systems are mounted on the rackshown in Figure 3, made of aluminium beams and plates designed for being mounted aboard the Airbus A310, in compliance with the guidelines provided by Novespace[31].

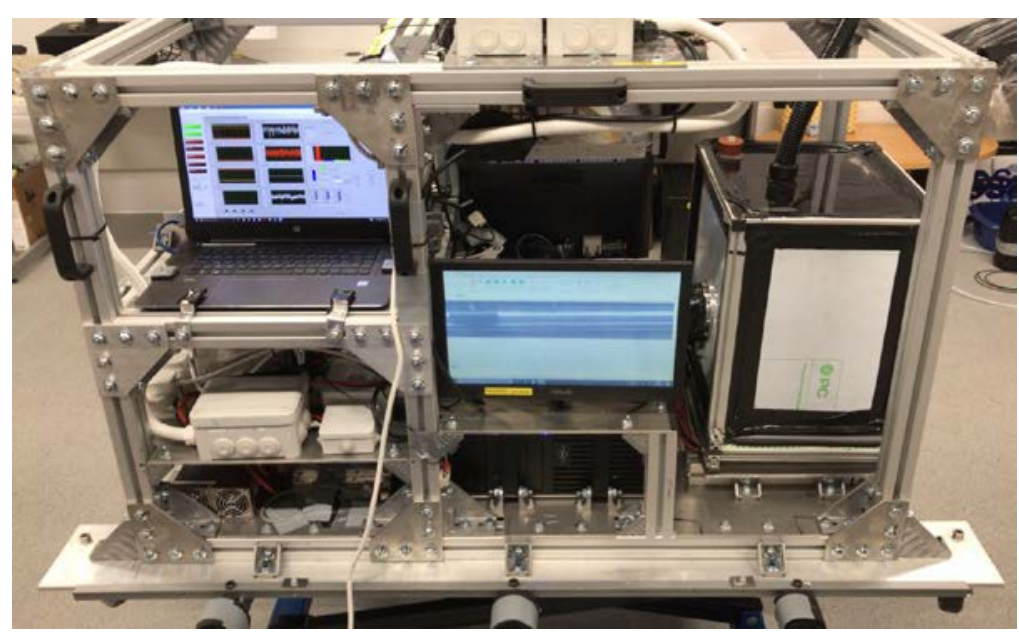

Figure 3: Experimental test rig for PF campaigns. \\ 2.2 Experimental procedure}

The $67^{\text {th }}$ ESA-Novespace Parabolic flight campaign took place in Bordeaux in November 2017. During each of the three flight days, thirty-one parabolic trajectories areperformed:the first one, called parabola zero, is followed by six sequences of five consecutive parabolae. In between each sequence, there are five minutes of steady flight at normal gravity level, used here to vary the heat power leveland let the system reach a steady state when possible. Eachparabola is composed by a first hyper-gravity period (20s $\pm 2 \mathrm{~s}$ at $1.8 \mathrm{~g})$, the microgravity period (20s $\pm 2 \mathrm{~s}$ at $0 \mathrm{~g}$ ) and a second hyper-gravity period equal to the first. The hypergravity and microgravity zones are recognizable by looking at the gravity acceleration measurements (first subplot) in the results section. A comprehensive description of the parabolic flight as a microgravity platform and of the manoeuvre is available in the work by Pletser [33]. 
Table 3: Experimental matrix during the flight.

\begin{tabular}{|c|c|c|c|}
\hline $\begin{array}{c}\text { Parabola } \\
\mathbf{N}^{\circ}\end{array}$ & DAY-I & DAY-II & $\begin{array}{c}\text { DAY-III } \\
\text { (start-up) }\end{array}$ \\
\hline 0 & $36 \mathrm{~W}$ & $18 \mathrm{~W}$ & $36 \mathrm{~W}$ \\
\hline $1-5$ & $52 \mathrm{~W}$ & $36 \mathrm{~W}$ & $36 \mathrm{~W}$ \\
\hline $6-10$ & $68 \mathrm{~W}$ & $52 \mathrm{~W}$ & $52 \mathrm{~W}$ \\
\hline $11-15$ & $96 \mathrm{~W}$ & $146 \mathrm{~W}$ & - \\
\hline $16-20$ & $134 \mathrm{~W}$ & - & $182 \mathrm{~W}(*)$ \\
\hline $21-25$ & $68 \mathrm{~W}$ & - & $134 \mathrm{~W}$ \\
\hline $26-30$ & $52 \mathrm{~W}$ & - & $68 \mathrm{~W}$ \\
\hline
\end{tabular}

The device has been tested in vertical position, bottom heated mode, at eight different power levels (18, 36, 52, 68, 96, 134, 146, 182 W). As shown in Table 3, the first two days were used for the thermalcharacterization, while the third one for the investigation of the start-up during the microgravity phase. With respect to the thermal characterization, the device is heated up at the desired power level before the microgravity period, and the power level is kept constant for the whole sequence, as already done in previous parabolic flight campaigns [13][14]. During the third day, the device is heated up after the occurrence of microgravity to prove that the PHP operation is not primed by the flow inertial effects, which are present in the 1-g and hyper-gravity phases. Each start-up test is repeated at leasttwice, and, after each start-up, several parabolaeare reserved to allow enough time for the whole system to cool down back to the target temperature of the Peltier cold side, set at $20^{\circ} \mathrm{C}$ for all the experiments. The asterisk in table 3 indicates that at $182 \mathrm{~W}$ the device has been tested both in start-up mode and in pseudo steady state.

\section{RESULTS}

It is worth to remind that the device is a hybrid system, acting as a Multiple Evaporator Loop Thermosyphon (MELT) when gravity acceleration is present, and as a capillary Pulsating Heat Pipe (PHP) in microgravity conditions [31]. In the present experiment, the minimum power that primes a stable circulation during the TS mode is $68 \mathrm{~W}$, corresponding to a wall to fluid average heat flux of $4.29 \mathrm{~W} / \mathrm{cm}^{2}$, which is the same minimum heat flux recorded during its thermal characterization on ground. To represent the gravity acceleration levels together with the heat input power levels and the data acquisition (temperatures, pressures etc.), temporal trends are showed in form of synoptic subplots (Figure 4). The "delta pressure" value $\Delta \mathrm{P}$ is the difference between the evaporator and the condenser pressure signal (black in Figure 4b); the fluid temperature signals are shown on a separate subplot (red line for the evaporator, blue line for the condenser); the "wall temperature" (see subplots 4d, 5d, 6e) comprises the temperatures acquired by all the thermocouples located on the external PHP surface:signals of the evaporator and condenser heat spreaders are shown in shades of red and blue respectively, while the temperatures on the tubes in the adiabatic zone are shown with shades of purple. The microgravity period is highlighted with a semitransparent vertical red band.

\subsection{Thermal response to microgravity}

As mentioned in the introduction, the microgravity period duration (about $20 \mathrm{~s}$ ) is not enough to reach a pseudosteady state (i.e. when the mean value of the oscillating temperature signal is constant in time), nevertheless it is useful to investigate the device thermo-hydraulic response in different conditions and to infer on the expected behaviour during the long-term microgravity environment available on the ISS. The PHP response to the microgravity conditions is separately discussed for the first two days (constant heat input) and the third day (startup). 


\subsubsection{Constant heat input}

Similarly to previous microgravity experiments performed on a simpler geometry with the same fluid, same internal diameter and same heat flux levels [13][14], the activation of flow motion and change of the operational regime, is always detected by all the measurements, including the visualization, immediately after the occurrence of microgravity. The difference with respect to the pressure signalrecorded for the simpler geometry is the absence of stop-over periods, which is a positive consequence of the higher number of heated zones. At low heat fluxes (below $68 \mathrm{~W}$ ), the vapor expansion is not able to start the fluid circulation in the gravity assisted mode.

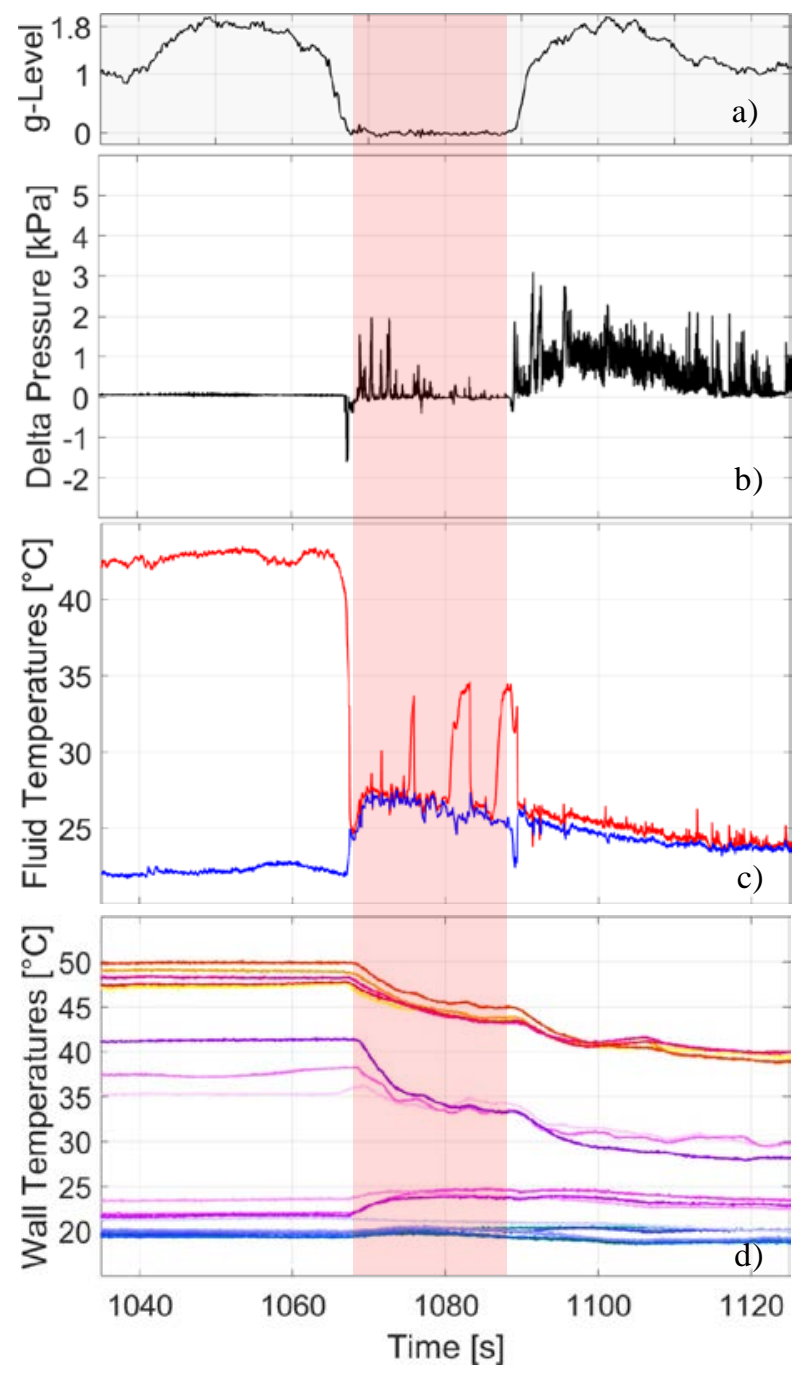

Figure 4: PHP thermal characterization during a typical parabola at a constant power of 36W (Day II, parabola 5): (a) glevel, (b) Pressure difference $\Delta$ P between the evaporator and condenser zone, (c) fluid temperatures (red for the evaporator, blue for the condenser); (d) wall temperatures (red shades for the evaporator, purple shades for the adiabatic, blue shades for the condenser zone).

The TS operation is characterized by frequent stopovers or even by the absence of flow motion: Figure $4 \mathrm{~b}$ shows that, during the first hyper-gravity level, when the heat power is $36 \mathrm{~W}$, the $\Delta \mathrm{P}$ between the evaporator and the condenser is zero and the fluid temperatures are steady (Figure $4 c, d$ ). With the occurrence of microgravity, the fluid $\Delta \mathrm{P}$ shows several peaks (Figure $4 \mathrm{~b}$ ) and the fluid temperatures initially become homogeneous and then oscillate (Figure 4c, d). Consequently, the wall temperature at the evaporator decreases. 
From $68 \mathrm{~W}$ up to the maximum heat power input, when gravity is present, the fluid circulation is stable when gravity is present. This is clearly visible, not only from the greyscale visualization (please refer to the video in the supplementary material), but also from the fluid pressure and temperatures trends, as shown in Figure 5. When the device is constantly heated at $182 \mathrm{~W}$, during $1 \mathrm{~g}$ and hyper-g (TS mode), the delta pressure is always positive, while during the microgravity phase (PHP mode) the fluid is oscillating without any stopover (Figure 4b), as also seen in a previous experiment on the same geometry onboard a sounding rocket [17].

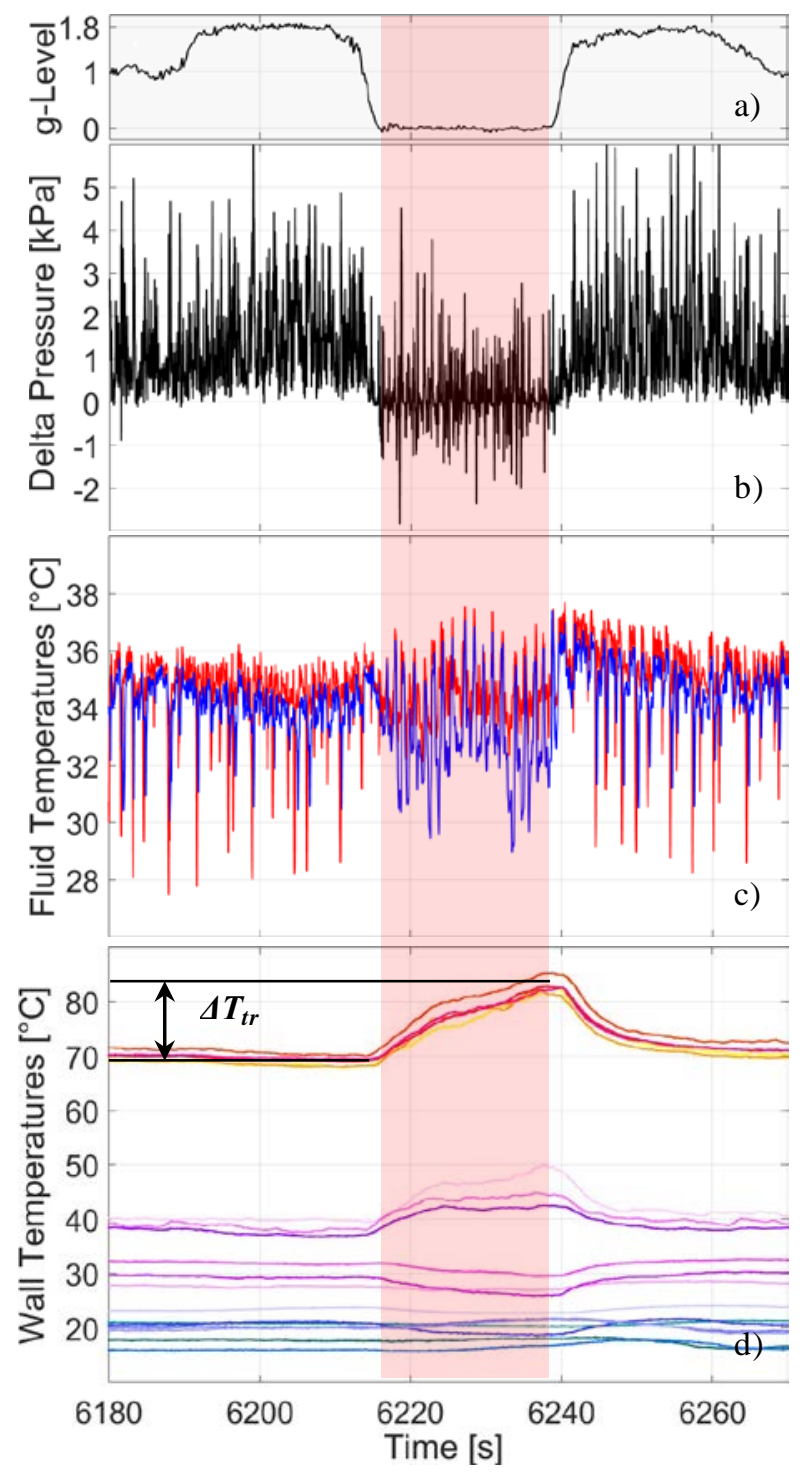

Figure 5: PHP thermal characterization during a typical parabola at a constant power of 182 W (Day III, parabola 20): (a) glevel; (b) Pressure difference $\Delta \mathrm{P}$ between the evaporator and condenser zone; (c) fluid temperatures (red for the evaporator, blue for the condenser); (d) wall temperatures (red shades for the evaporator, purple shades for the adiabatic, blue shades for the condenser zone).

The stable fluid circulation reached in TS mode during 1g and hyper-gravity (Video1_182W_Hyg_0.125x: annular flow coming from the evaporator zone on the left side) allows the system to reach a pseudo steady state, as shown by the flat trend of all the temperature signals in Figure 5d. During the micro-gravity period (Video2_182W_ug_0.125x: oscillating semi-annular/slug flow), the flow pattern transition from annular circulating regime to slug-plug oscillation results in a decrease of the heat transfer rateand the consequent increase of the evaporator temperatures. The stopover periods, that were more frequent in a similar device with a smaller number of heated sections [13], are not present here and this is beneficial in terms of thermal transient after the occurrence of micro-gravity. The two devices are filled with the same working fluid, the tube material and channel characteristics as well as the wall to fluid heat fluxes are also the same. The difference resides in the smaller 
1 number of turns, (and consequently in a smaller number of heated sections) in the evaporator section. The higher 2 number of turns increase the probability that pressure impulses occur inside the device, stabilizing the thermal 3 behaviour. This is noticeable by calculating the difference between the average temperature of the evaporator, 4 evaluated at the beginning and at the end of the microgravity period (fig. 5d).

$$
\Delta T_{t r}=\overline{T_{e}}\left(t_{\text {start }, 0 g}\right)-\overline{T_{e}}\left(t_{e n d, 0 g}\right)
$$

5 Where $\bar{T}_{e}=\left(\sum_{n} T_{n}\right) / n$ is the average of the five temperature measurements in the evaporator zone and $t_{i, 0 g}$ and $6 \quad t_{f, 0 g}$ are respectively the microgravity starting and ending time.

Table 4: Comparis on of the evaporator temperature differences during the microgravity phase between the 5-turns (Mangini et al. [13]) and the 14-turns SpacePHP.

\begin{tabular}{|c|c|c|c|c|c|}
\hline \multicolumn{3}{|c|}{$\begin{array}{c}\text { 5 turns } \\
\text { (Mangini et al. [13]) }\end{array}$} & \multicolumn{3}{c|}{$\begin{array}{c}14 \text { turns } \\
\text { (present work) }\end{array}$} \\
\hline Q[W] & $\left.\boldsymbol{q ”}^{\mathbf{W}} / \mathbf{c m}^{2}\right]$ & $\boldsymbol{\Delta T}_{\boldsymbol{t r}}[\mathbf{K}]$ & $\boldsymbol{Q}[\mathbf{W}]$ & $\mathbf{q}\left[\mathbf{W} / \mathbf{c m}^{2}\right]$ & $\boldsymbol{\Delta T}_{\boldsymbol{t r}}[\mathbf{K}]$ \\
\hline 30 & 3.18 & 3 & 52 & 3.28 & 0 \\
\hline 40 & 4.24 & 10 & 68 & 4.29 & 3 \\
\hline 80 & 8.48 & 20 & 134 & 8.46 & 15 \\
\hline 120 & 12.73 & 40 & 182 & 11.49 & 13 \\
\hline
\end{tabular}

The wall to fluid heat flux as is the total heat power level $Q$ divided by the internal tube wall surface in the evaporator zone $A_{w f}$.

$$
q^{\prime \prime}=Q / A_{w f}
$$

For the simpler geometry $A_{w f}=9.4 \mathrm{~cm}^{2}$, while for the present case $A_{w f}=15.8 \mathrm{~cm}^{2}$. Table 4 shows the comparison between the two geometries in terms of total heat power, relative heat fluxes and temperature differences. Note that the comparison is made at the same heat flux level. The present case is characterized by smaller transient temperature differences for all the heating powers. 


\subsubsection{Start-up during microgravity}

The tests consist in switching the power supply on immediately after the occurrence of microgravity. The first objective is to verify that the activation of the fluid motion is not primed by residual inertial effects due to the previous hyper-gravity period. The second objective is to understand the effect of the heat input level on thestartup.

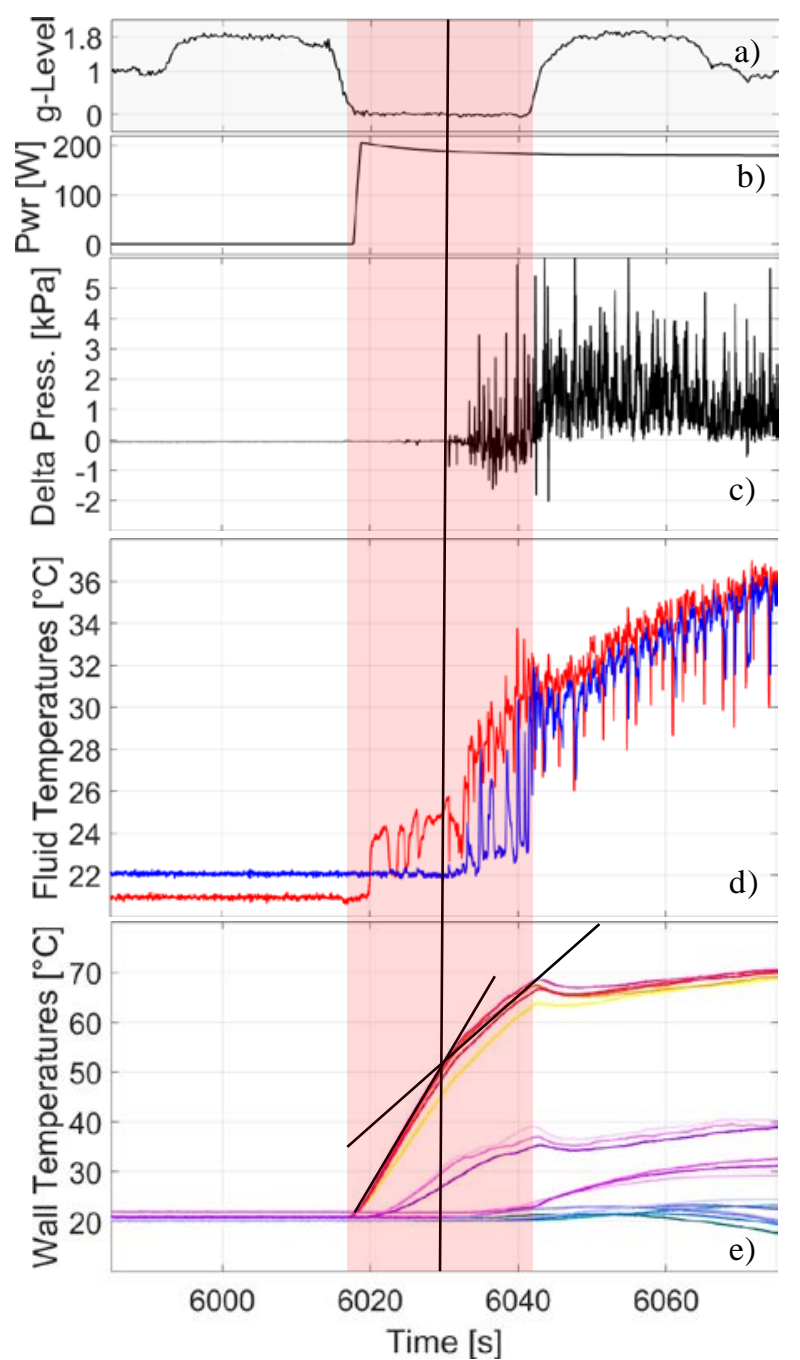

Figure 6: PHP thermal characterization during a start-up test at 182W: (a) g-level, (b) Heat load, (c) Pressure difference $\Delta \mathrm{P}$ between the evaporator and condenser zone, (d) fluid temperatures (red evap., blue cond.) and (e) wall temperatures.

At low heat power levels ( 36 and 52W) the full start-up is not observed: only the fluid temperature at the evaporator shows some fluctuation, but all the other sensors, as well as the visualization, do not indicate any perturbation. From $68 \mathrm{~W}$, the fluid motion activation is clear from all the sensors as well as from the visualization with confirmed repeatability of the phenomenon. Figure 6 shows the device response at $182 \mathrm{~W}$. A graph related to the power input is also added (Figure 6b). Likewise, at lower heat flux levels, while the fluid is still not moving, the fluid temperature signal at the evaporator starts to oscillate (Figure 6d). Only when the fluid temperature at the condenser starts varying, the $\Delta \mathrm{P}$ starts oscillating (Figure 6c), and a slug/plug flow is also recorded by the cameras. The activation of the fluid motion, highlighted with a verticaldashed line, results in an increase of the overall heat transfer rate. Consequently, the temperature increase at the evaporator is also attenuated, as shown in Figure 6e.

\subsection{Analysis of local themodynamic states}

In real two-phase dynamic systems, the fluid thermodynamic state is often far from the equilibrium conditions. The simultaneous measurement of the local fluid pressure and temperature $\left(P_{f}, T_{f}\right)$ allows to compare the actual thermodynamic state with the corresponding saturated conditions, and hence to quantify the superheating and 
subcooling levels close both to the evaporator and to the condenser sections. Notice that the microgravity condition has been exploited here to eliminate the hydrostatic pressure component which would be difficult to estimate. The superheating and subcooling levels are evaluated in terms of temperature difference between the measured fluid state and the equilibrium state along the saturation curve. Given that the fluid saturation temperature at the actual measured pressure $T_{s}\left(P_{f}\right)$ is calculated by means of the REFPROP 9.0 software released by NIST [34], the temperature difference $\Delta T_{s}$ is:

$$
\Delta "_{\#}="_{\%}-{ }_{\#}(\text { () }
$$

To describe the different thermodynamic states and processes that may occur in a liquid/vapor system the qualitative state diagrams in Figure 7 are presented, i.e. the pressure-temperature(Fig. 7a) and the pressure-specific volume (Fig. 7b). For example, if the fluid is superheated $\Delta T_{\mathrm{s}}>0$ (on the right side of the saturation curve in Fig. 7a) there may be three different conditions depending on mechanical stability:

$$
\frac{*^{+(\%)}}{+\%}-<0
$$

(i.e. an isothermalfluid compression yields to a specific volume decrease):i) superheated vapor (E-F dotted line in Fig. 7b); ii) metastable superheated liquid ( $\Delta T_{s}<\delta T_{1, \text { max }}$ in Fig. 7a and B-C dotted line in Fig. 7b) where the liquid is mechanically stable even if its temperatureis above the saturation condition meaning that a finite quantity of energy may be provided to the fluid without undergoing a phase change; iii) unstable superheated liquid $\left(\Delta T_{s}>\right.$ $\delta T_{1, \max }$ in Fig. 7a and C-D dotted line in Fig. 7b), meaning that any infinitesimal disturbance would trigger the evaporation.

a)

a) $P$

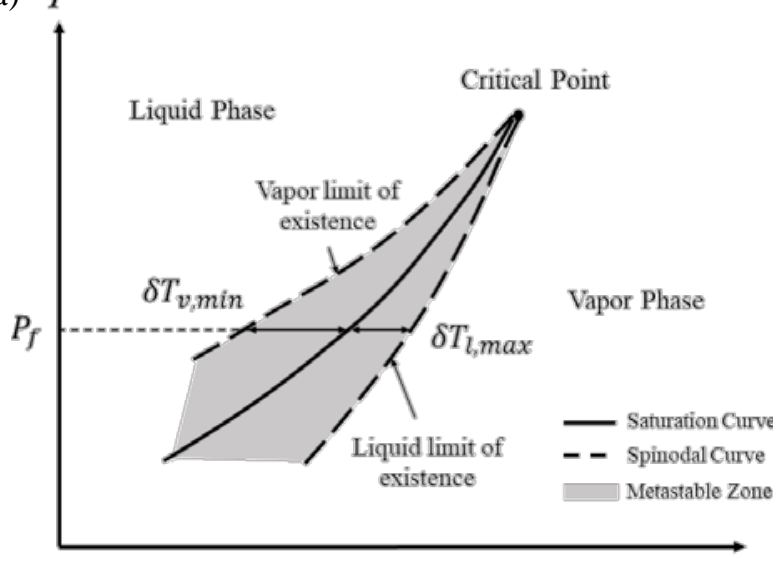

b) $P$

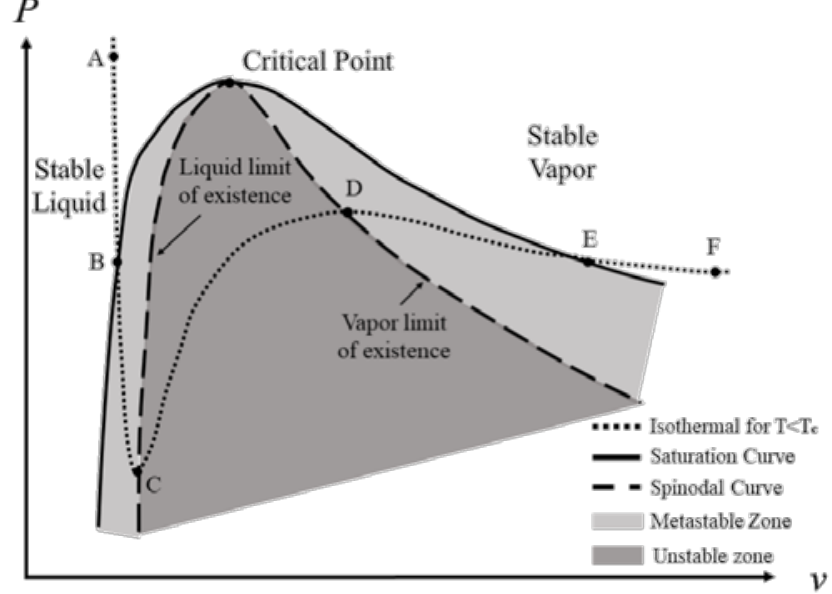

Figure 7: Vapor and liquid phase change and thermodynamic states:a) Pressure-Temperature; b) Pressure-Specific volume.

Analogous and complementary considerations can be made when $\Delta T_{s}<0$ and they are all resumed in the first three columns of Table 5. Note the loci where equation 2 is equal to zero ( $\mathrm{C}$ and $\mathrm{D}$ in Fig. $7 \mathrm{~b}$ ) represent the limit of existence of the metastable superheated liquid and the metastable subcooled vapor relatively also known as spinodal limits. 
Table 5: List of the thermodynamic states for the presentcase.

\begin{tabular}{|c|c|c|c|c|c|c|}
\hline CASE & PHASE & $\begin{array}{l}\text { THERMODYNAMIC } \\
\text { STATE } \\
\end{array}$ & \multicolumn{2}{|c|}{$\begin{array}{c}\text { THERMODYNAMIC } \\
\text { PROCESS } \\
\end{array}$} & $\begin{array}{l}\text { LATENT/ } \\
\text { SENSIBLE }\end{array}$ & PRESENT CASE \\
\hline \multirow{6}{*}{$\Delta T_{s}>0$} & \multirow{2}{*}{ Vapor } & \multirow{2}{*}{$\begin{array}{l}\text { Superheated } \\
\text { (Stable) }\end{array}$} & $1_{23}$ & Heating & Sensible & \multirow{2}{*}{$\begin{array}{l}\text { Only lat ent because of the } \\
\text { thin liquid film wettingthe } \\
\text { thermocouple bead. }\end{array}$} \\
\hline & & & $1_{456}$ & $\begin{array}{l}\text { Cooling down } \\
\text { to saturation }\end{array}$ & Sensible & \\
\hline & \multirow[t]{2}{*}{$\begin{array}{c}\text { Liquid } \\
\Delta "_{\#}<7_{9, ;<=}\end{array}$} & \multirow[t]{2}{*}{$\begin{array}{l}\text { Superheated } \\
\text { (Metastable) }\end{array}$} & $1_{23}$ & $\begin{array}{l}\text { Heatingup to } \\
\text { spinodal limit } \\
\text { and/or } \\
\text { evaporation }\end{array}$ & $\begin{array}{l}\text { Sensible }+ \\
\text { Latent }\end{array}$ & \multirow[t]{2}{*}{$\begin{array}{l}\text { The sensibleterm is } \\
\text { measurable if phase is } \\
\text { detected }\end{array}$} \\
\hline & & & $1_{456}$ & Cooling & Sensible & \\
\hline & \multirow{2}{*}{$\begin{array}{c}\text { Liquid } \\
\Delta "_{\#}>7{ }_{9, ;<=}\end{array}$} & \multirow{2}{*}{$\begin{array}{l}\text { Incipient Evaporation } \\
\text { (Unstable) }\end{array}$} & $71_{23}$ & Evap oration & Latent & \multirow{2}{*}{ Not measurable } \\
\hline & & & $71_{456}$ & Evaporation & Latent & \\
\hline \multirow{6}{*}{$\Delta T_{s}<0$} & \multirow[t]{2}{*}{ Liquid } & \multirow{2}{*}{$\begin{array}{l}\text { Subcooled } \\
\text { (Stable) }\end{array}$} & $1_{23}$ & $\begin{array}{l}\text { Heating up to } \\
\text { saturation }\end{array}$ & Sensible & \multirow{2}{*}{$\begin{array}{l}\text { The sensibleterm is } \\
\text { measurable if phase is } \\
\text { detected }\end{array}$} \\
\hline & & & $1_{456}$ & Cooling & Sensible & \\
\hline & \multirow[b]{2}{*}{$\begin{array}{c}\text { Vapor } \\
\Delta "_{\#}<7 "_{>, ; 23}\end{array}$} & \multirow[b]{2}{*}{$\begin{array}{l}\text { Subcooled } \\
\text { (Metastable) }\end{array}$} & $1_{23}$ & Heating & Sensible & \multirow[b]{2}{*}{$\begin{array}{l}\text { Only latent because of the } \\
\text { thin liquid film wetting the } \\
\text { thermocouplebead. }\end{array}$} \\
\hline & & & $1_{456}$ & $\begin{array}{l}\text { Cooling down } \\
\text { to spinodal } \\
\text { and/or } \\
\text { condensation } \\
\end{array}$ & $\begin{array}{l}\text { Sensible }+ \\
\text { Latent }\end{array}$ & \\
\hline & \multirow{2}{*}{$\begin{array}{c}\text { Vapor } \\
\Delta "_{\#}>7{ }^{\prime}, ; 23\end{array}$} & \multirow{2}{*}{$\begin{array}{c}\text { Incipient Condensation } \\
\text { (Unstable) }\end{array}$} & $71_{23}$ & Condensation & Latent & \multirow{2}{*}{ Not measurable } \\
\hline & & & $71_{456}$ & Condensation & Latent & \\
\hline
\end{tabular}

The fourth and fifth columns of Table 5 show the possible thermodynamic processes and the corresponding type of heat transfer the system may undergo, depending whether energy is provided or subtracted to the fluid, respectively $E_{\text {in }}$ and $E_{\text {out }}$. Focusing again on the case when $\Delta T_{s}>0$ : the stable vapor shall be heated towards other stable superheated states or cooled down to the saturated conditions and in both cases no phase change occurs meaning that the fluid undergoes only sensible heat transfer; the metastable superheated liquid shall be heated up to the spinodal limit undergoing sensible and possibly latent heat depending on the thermal energy input and on the system fluid dynamic conditions, or shall be just cooled down towards another metastable or even a stable liquid state undergoing only sensible heat. Finally, the unstable superheated liquid is going to evaporate for any small thermal energy entering or exiting the fluid.

The last column of Table 5 translates such thermodynamic considerations into what may happen in the present PHP system. Since the fluid is highly wettable, the thermocouple bead is most likely covered by a thin liquid film, meaning that even if either a stable superheated vapor or the liquid film surrounding the vapor is subjected to a transient dry-out, phase change occurs at the film-vapor interface: hence, the thermocouple measurement is not representative of the real vapor temperature, as it should be attributed to latent heat exchange. On the other hand, the superheated metastable liquid temperature is measurable, but a local void fraction measurement would be needed to distinguish this state from the previous case. In other words, it would be possible to detect the metastable states only by implementing a local phase detection probe at the same location of the temperature and pressure measurements. The temperature of an unstable fluid is not measurable since phase change phenomena are much more rapid than the thermocouple thermalinertia. Moreover, the fluid dynamic conditions and the presence of the probe itself are not compatible with the existence of unstable conditions. 

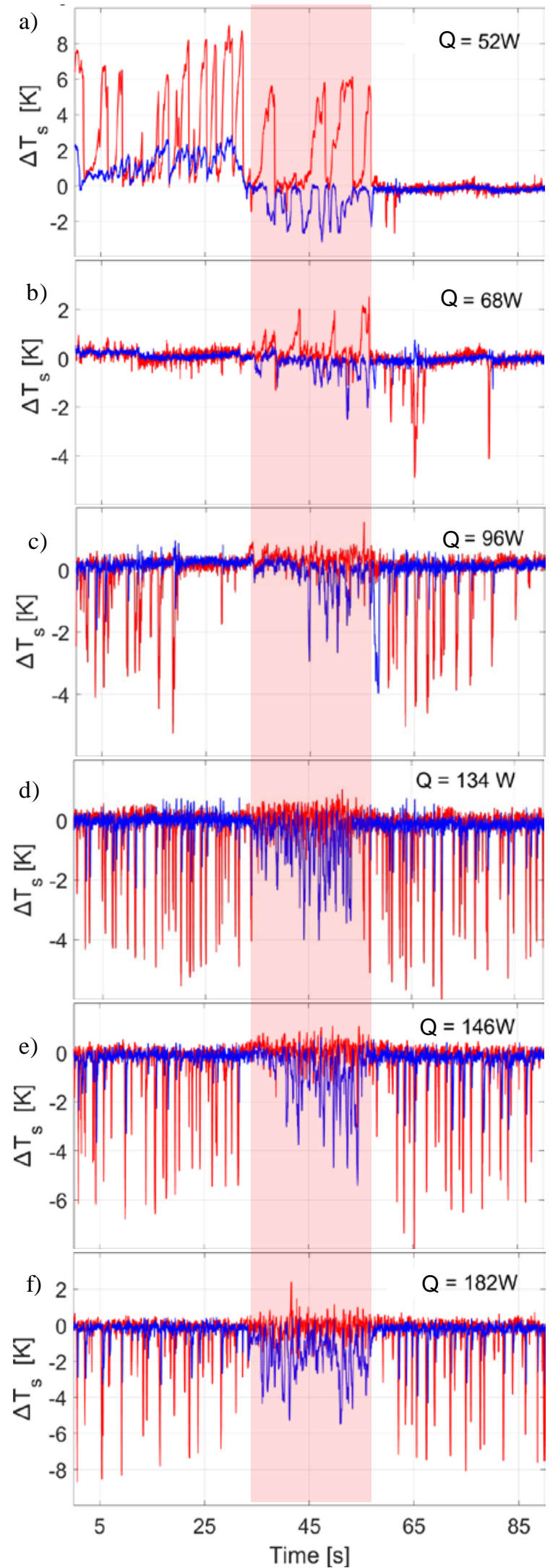

2 Figure 8: Time evolution of the saturation temperature difference during microgravity (semi-transparent vertical red stripe) 3 at different heat power levels (red: evaporator zone, blue: condenser zone), the last parabola of each parabola sequence. 
At low heat inputs (Fig. 8a), the flow motion is weak, and the fluid batches are in a stagnant condition, resulting in large superheating levels at the evaporator and large subcooling at the condenser. Increasing the heat input, the flow oscillations are stronger and consequently the fluid batches reside at the same location for a shorter time, resulting in a decrease of the superheating level at the evaporator and to a stable oscillation around a null temperature difference, i.e. closer to the saturation state. The statistics in terms of average, standard deviation, maximum and minimum temperature differences during microgravity are shown only for the constant heat input levels (68 W, $96 \mathrm{~W}, 134 \mathrm{~W}, 146 \mathrm{~W}$ ) which are the cases where a stable circulation was achieved before microgravity. The maximum and minimum temperature differences are simply the maximum and minimum values recorded during the microgravity period while the average temperature is the time averaged temperature overthe microgravity period.
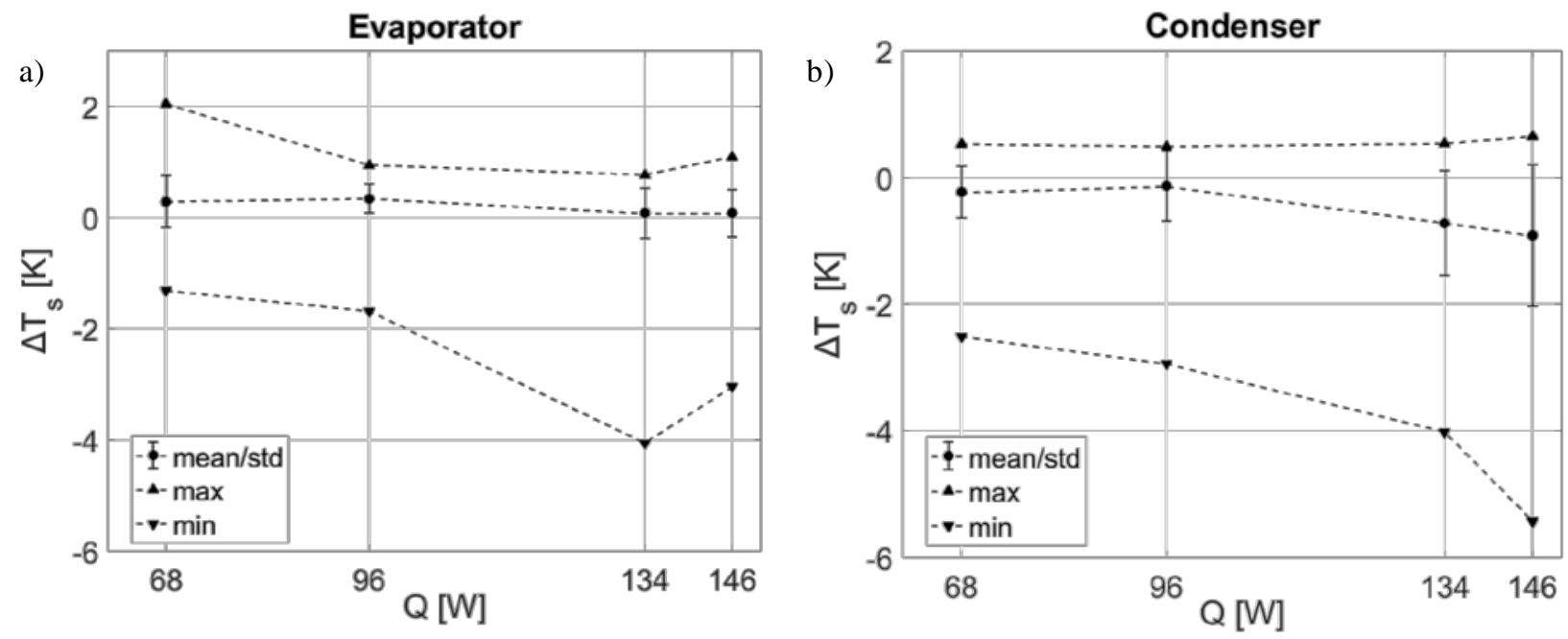

Figure 9: Statistics of the saturation temperature difference during microgravity at different heat input levels: a) evaporator; b) condenser.

As shown in figure 9, temperature difference peaks range from $-5 \mathrm{~K}$ to $+2 \mathrm{~K}$. The average value in the evaporator section is slightly above zero meaning that the evaporator is mainly superheated, nevertheless the minimum peaks of subcooling are higher than the maximum superheating level that never exceeds $2 \mathrm{~K}$. On the other hand, the average value in the condenser section is slightly below zeromeaning that the condenser is mainly sub-cooled, and the superheating level peaks are always under $1 \mathrm{~K}$. The subcooling level increases with the heat load both at the evaporator and the condenser.

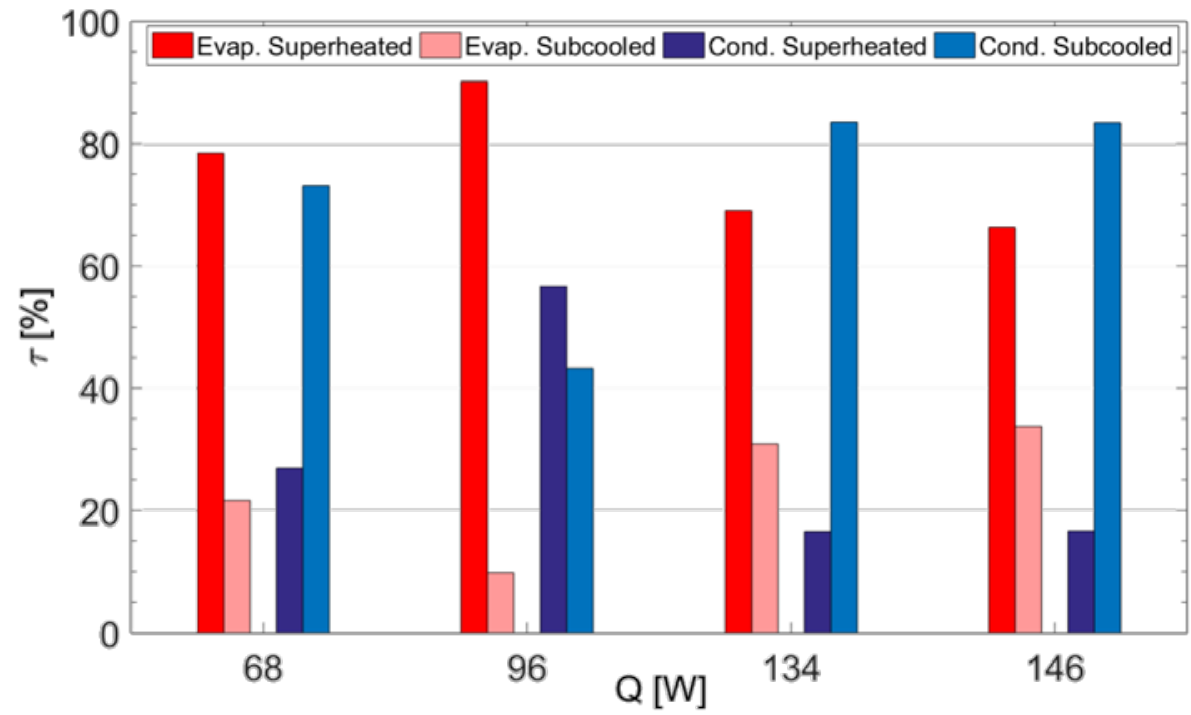

Figure 10: superheated and subcooled time percentage in the evaporator (red shades) and in the condenser (blue shades) zone. 
For the present case, the superheating and subcooling levels depend on the pseudo steady dynamic of the system, on the system geometry (confined flow) and on the peculiar boundary conditions: namely the wall to fluid surface ratio between condenser and evaporator(the wall to fluid heat exchange area is smaller in the evaporator zone than the condenser) and the random distribution on the phases inside the device. These factors, together with the heat input level, affect the fluid local speed and the average regime (oscillating/circulating), the local phase (liquid slug/vapor plug) and the presence or absence of liquid film surrounding the vapor plugs. These phenomena determine how much time the fluid resides in the heat exchange zones respectively (evaporator and condenser) and what kind of heat transfer mode is occurring (sensible or latent, in a stable state or in a metastable state).

Figure 10 shows the superheating and subcooling time percentage $\tau$ with respect to the whole microgravity period for the evaporator (red shades) and the condenser (blue shades). As expected, the time of superheat is longer in the evaporator zone (around $70 \%$ of the whole microgravity period) for all the heat input levels and the condenser is subcooled most of the time (around 80\%) for all the heat input levels, except for the case at $96 \mathrm{~W}$ where the subcooling time is slightly lower but still around $40 \%$. The existence of subcooling at the evaporator, and its increasing trend with the increase of the heat load level is less intuitive but can be qualitatively explained by the combined effect of a bigger condenser surface with respect to the evaporator and the increase of the overall fluid motion at higher heat input levels. As the heat load increases, the fluid can travel longer distances, can be transported for a longer time through the condenser and refreshes the evaporator more often than the fluid coming back from the adiabatic zone in case of small amplitude oscillations. Furthermore, the increase in the dynamic effects bring to a higher level of thermodynamic non equilibrium, augmenting the probability to that sensible heat is exchanged through a metastable state rather than latent heat occurs close to saturated conditions. In the future, when the localvoid fraction measurement will be implemented at the same location of the temperature and pressure probes, it will be possible to distinguish between stable and metastable states, and even to attempt an estimation of the wall-to-fluid sensible and latent heattransfer.

\section{CONCLUSIONS}

The thermal characterization of a hybrid TS/PHP prototype under a varying gravity field is presented here to prove the feasibility of a future experiment onboard the Intemational Space Station. The device is equipped with temperature and pressure sensors as well as with a transparent sapphire insert for the simultaneous high-speed imaging acquisition. The main research outcomes are listedbelow:

- In comparison with a previous experiment with a smaller number of heated sections [13], the absence of stopover periods is beneficial in terms of heat transfer rate. Indeed, for the same wall-to-fluid heat input flux, the temperature difference at the evaporator between the beginning and the end of the microgravity periods is always smaller with the present PHP.

- Novel start up tests, where the heat load is provided after the occurrence of microgravity, show that the 20s microgravity period is enough for the device activation device and that, most important, prove that the PHP operation is not primed by the flow inertial effect, still present when the device is activated before the microgravity period.

- The different kind of local thermodynamic states in the PHP have been discussed. A technique for the simultaneous measurement of the fluid pressure and temperature has been successfully implemented on a hybrid TS/PHP and tested in microgravity conditions showing the existence of subcooled and superheated local thermodynamic states.

- In the present case the evaporator is mainly superheated and the condenser is mainly subcooled but the subcooling level and time percentage increase with the heat input level. The difference between the actual fluid temperature and the corresponding saturated temperature records peaks from $-5 \mathrm{~K}$ to $+2 \mathrm{~K}$ when a stable circulation was achieved before microgravity.

- Further work to detect the local fluid phase in the measurement location is needed to distinguish stable and metastable states. 
The present work is carried forward in the framework of the ESA MAP Project INWIP and the EPSRC UK HyHP Project (EP/P013112/1). Thanks to the NOVESPACE team in Bordeaux, and especially to Ms. Alexandra Jacquemet for their ground and flight technical support. Thanks to Davide Fioriti, Roberto Manetti, Massimo Ciampalini, Franco Peticca, Davide Della Vista for their essential technical contribution and toMarco Bernagozzi and Matteo Pozzoni for their support and the participation to the campaign. Special thanks to Dr. Balazs Toth for his constant interest and support. Furthermore, the team would like to thank the TRP project, and the laboratory TEC-MMG at ESA/ESTEC for lending the MWIR camera.

NOMENCLATURE

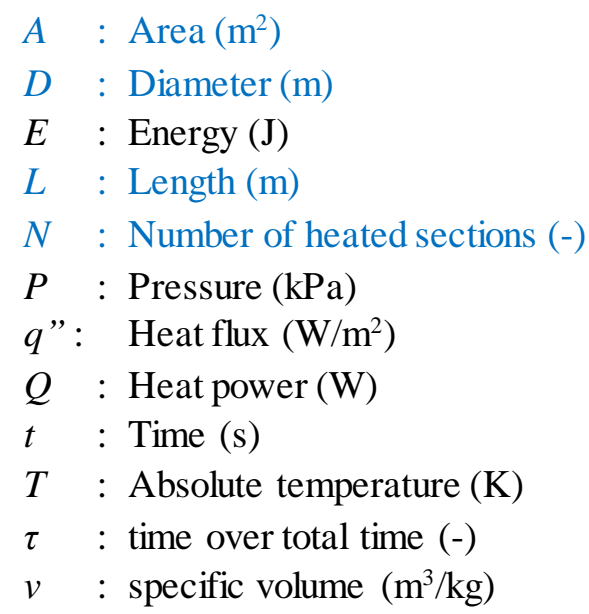

c : condenser

$e$ : evaporator

end : end

$f \quad$ : fluid

in : entering the system

min : minimum

$\max$ : maximum

ou : leaving the system

$s \quad$ : saturated conditions

start : start

$T$ : isothermal

tr : transient

wf : wall to fluid

\section{Subscripts}

\section{REFERENCES}

[1] Gilmore, D. G., Spacecraft Control Handbook, Fundamental Technologies, Second Edition, Vol. 1, The Aerospace Corp., AIAA Publ.,(2002).

[2] Sunden, B., Fu, J., Heat Transfer in Aerospace Applications, Academic Press, (2017) 117-144.

[3] Bastakoti D., Zhanga H., Lia D., Caia W., Li F., An overview on the developing trend of pulsating heat pipe and its performance, App. Therm. Eng., 141 (2018) 305-332.

[4] Mameli, M., Araneo, L., Filippeschi, S., Marelli, M., Testa, R., Marengo, M., Thermalperformance of a closed loop pulsating heat pipe under a variable gravity force, Int. J. Ther. Sci. 80 (2014) 11-22. 
[5] Gu, J., Kawaji, M., Futamata, R., Effects of gravity on the performance of pulsating heatpipes, J. Thermophys. Heat Trans. 18 (2004) 370-378.

[6] Gu, J., Kawaji, M., Futamata, R., Microgravity performance of micro pulsating heating pipe, Micrograv. Sci. Technol. 16 (2005) 179-183.

[7] Ayel, V., Araneo, L., Scalambra, A., Mameli, M., Romestant, C., Piteau, A., Marengo, M., Filippeschi, S. Bertin, Y., Experimentalstudy of a closed loop flat plate pulsating heat pipe under a varying gravity force, Int. J. Therm. Sci. 96 (2015) 23-34.

[8] Taft, B.S., Laun, F.F., Smith, S., Microgravity performance of a structurally embedded oscillating heat pipe, J. Thermophys. Heat Transfer 29 (2) (2015).

[9] De Paiva, K.V., Mantelli, M.B.H., Slongo, L.K., Burg, S.J., Experimental tests of mini heat pipe, pulsating heat pipe and heat spreader under microgravity conditions aboard suborbital rockets, Proc. of the 15th IHPC, Clemson, South Carolina, USA, 2010.

[10]De Paiva, K.V., Mantelli, M.B.H., Florez, J.P.M., Nuernberg, G.G.V., Mini heat pipe experiments under microgravity conditions. What have we learned? Proc. of the 17th IHPC, Kanpur, India, 2013.

[11]Daimaru T., Nagai H., Ando M., Tanaka K., Okamoto A., Sugita H., Comparison between numerical simulation and on-orbit experiment of oscillating heat pipes, International Journal of Heat and Mass Transfer 109 (2017) 791-806.

[12]Ando M., Okamoto A., Tanaka K., Maeda M., Sugita H., Daimaru T., Nagai H., On-Orbit Demonstration of Oscillating Heat Pipe with Check Valves for Space Application, App. Therm. Eng., 130 (2018) 552-560.

[13]Mangini, D., Mameli, M., Geourgoulas, A., Araneo, L., Filippeschi, S., Marengo, M., A pulsating heat pipe for space applications: ground and microgravity experiments, Int. J. Therm. Sci. 95 (2015) 53-63.

[14]Mangini D., Mameli M., Fioriti D., Araneo L., Filippeschi S., Marengo M., Hybrid Pulsating Heat Pipe for Space Applications with Non-Uniform Heating Patterns: Ground and Microgravity Experiments, App. Therm. Eng. 126 (2017) 1029-1043.

[15]Ayel, V., Araneo, L., Marzorati, P., Romestant, A., Bertin, Y., Marengo, M., Visualization of Flow Patterns in Closed Loop Flat Plate Pulsating Heat Pipe Acting as Hybrid Thermosyphons under Various Gravity Levels, Heat Transfer Engineering, DOI:10.1080/01457632.2018.1426244.

[16]Cecere A., De Cristofaro D., Savino R., Ayel V., Sole-Agostinelli T., Marengo M., Romestant C., Bertin Y., Experimental Analysis of a Flat Plate Pulsating Heat Pipe with Self-Rewetting Fluids during a Parabolic Flight Campaign, Acta Astronautica, 147 (2018) 454-461.

[17] Mameli M., Piacquadio S., Viglione A., Catarsi A., Bartoli C., Marengo M., Di Marco P., Filippeschi S., Start-Up and Operation of a 3D Hybrid Pulsating Heat Pipe on Board a Sounding Rocket, Microgravity Science and Technology International Journal, 2019, DOI: https //doi.org/10.1007/s12217-019-9682-5.

[18]Zell, M., Ngo-Anh, J., Hatton, J., Minster, O., Istasse, E., Demets, R., Toth, B., Schoonejans, P., Heppener, M., Straube, U., Dieckmann, M., Weems, J., ESA science and applications programme on ISS, International Astronautical Congress, Vol. 5, pp. 3911-3933, 12-16 October 2015, Jerusalem, Israel.

[19]Nikolayev V., Marengo M., Pulsating Heat Pipes: Basics of Functioning and Numerical Modeling, in: J. R. Thome (Ed.), Encyclopedia of Two-Phase Heat Transfer and Flow IV, vol. 1: Modeling of Two-Phase Flows and Heat Transfer, World Scientific, ISBN 978-981-3234-36-9, 63, http://www.worldscientific.com/worldscibooks/10.1142/10831, 2018.

[20]Bruce R., Barba M., Bonelli A., Baudouy B., Thermal performance of a meter-scale horizontal nitrogen Pulsating Heat Pipe, Cryogenics, Vol. 93, July 2018, Pages 66-74.

[21]Nikolayev V., Nekrashevych I., Vapor thermodynamics and uid merit for pulsating heat pipe, Joint 19th International Heat Pipe Conference and 13th International Heat Pipe Symposyum, Pisa, Italy, June 10-14, 2018.

[22]Bonnet F., Gully P., Nikolayev V., Experimental study of a single branch cryogenic pulsating heat pipe: first results, Proc. Eurotherm Sem. On Gravitational Effects on Liquid-Vapour Phase Change, IUSTI, Hyeres, France, 2011. 
[23] Gully P., Bonnet F., Nikolayev V., Luchier N., Tran T.Q., Evaluation of the vapour thermodynamic state in PHP, Proc. 17th International Heat Pipe Conference, IIT Kanpur, Kanpur, India, 2013.

[24] Rao M, Lefevre F, Khandekar S, Bonjour J., Understanding transportmechanism of a self-sustained thermally driven oscillating two-phase system in a capillary tube. Int J Heat Mass Transf., 2013;65:451e9.

[25] Rao M, Leevre F, Khandekar S, Bonjour, Mechanisms of a self-sustained thermally driven oscillating LiquidVapour meniscus. Int J. Heat Mass Transf 2015; 86:519e30.

[26] Jun S., Kim S. J., Experimental investigation on the thermodynamic state of vapor plugs in pulsating heat pipes, International Journal of Heat and Mass Transfer 134 (2019) 321-328.

[27] Mangini M., Marengo M., Araneo L., Mameli M., Fioriti D., Filippeschi S., Infrared Analysis of the TwoPhase Flow in a Single Closed Loop Pulsating Heat Pipe, Exp. Therm. and Fluid Sci. Journal, Vol 97, pp. 304-312, 2018, https:/doi. org/10.1016/j.expthermflusci.2018.04.018, 2018.

[28] Catarsi A., Fioriti D., Mameli M., Filippeschi S., Di Marco P., Accuracy Analysis of Direct Infrared Temperature Measurements of Two-Phase Confined Flows, 16th International Heat Transfer Conference, IHTC-16, August 10-15, 2018, Beijing, China (DOI: 10.1615/IHTC16.tpm.024202, pages 8943-8953).

[29] Pietrasanta L., Mangini D., Fioriti D., Miche N., Georgoulas A., Andredaki M., Araneo L., Marengo M., A single loop pulsating heat pipe in varying gravity conditions: experimental results and numerical simulations, in 16th International Heat Transfer Conference, IHTC-16, Beijing, China, 10-15 August, 2018, DOI: 10.1615/IHTC16.her.023891.

[30]Moffat RJ. Describing the uncertainties in experimental results, Exp. Therm. Fluid. Sci. (1988); Vol 1, pp. 317, https://doi.org/10.1016/0894-1777(88)90043-X.

[31]Mameli M., Mangini D., Vanoli G., Filippeschi S., Araneo L., Marengo M., Advanced Multi-EvaporatorLoop Thermo-syphon, Energy, 112 (2015) 562-573.

[32]Gai F., Experiment Design Guidelines in Parabolic Flight, GDL-2016-01, NOVESPACE 15, rue des Halles 75001 Paris - France.

[33]Pletser V., European aircraft parabolic flights for microgravity research, applications and exploration: A review, Reach - Rev. Hum. Sp. Explor., vol. 1, pp. 11-19, 2016. http://dx.doi.org/10.1016/j.reach.2016.05.002.

[34] Lemmon E.W., Huber M. L., McLinden M. O., NIST Standard Reference Database 23: Reference Fluid Thermodynamic and Transport Properties-refprop, Version 9.0, National Institute of Standards and Technology, Standard Reference Data Program, Gaithersburg Maryland 20899, 2013. 